\title{
INTERFERÊNCIA PEDAGÓGICA NA AVALIAÇÃO DA APRENDIZAGEM NO ENSINO PRESENCIAL E A DISTÂNCIA COM O USO DE TECNOLOGIAS
}

\author{
INTERFERENCIA PEDAGÓGICA EN LA EVALUACIÓN DEL APRENDIZAJE EN \\ LA ENSEÑNANA PRESENCIAL Y LA DISTANCIA CON EL USO DE \\ TECNOLOGÍAS
}

\author{
PEDAGOGICAL INTERFERENCE IN THE EVALUATION OF LEARNING IN \\ PRESENT TEACHING AND THE DISTANCE WITH THE USE OF \\ TECHNOLOGIES
}

\author{
Ivo José BOTH ${ }^{1}$ \\ Mary Ângela Teixeira BRANDALISE ${ }^{2}$
}

RESUMO: Este texto tem por objetivo discutir o papel da avaliação para aprendizagem do educando com o uso das tecnologias, independentemente da modalidade de ensino - presencial ou a distância -, e para a variação de instrumentos avaliativos como parte de um planejamento que é retroalimentado pelas demandas surgidas no processo de ensino e aprendizagem. $O$ texto subdivide-se em duas partes, em que na primeira são focadas ambiências que necessariamente acodem e ajudam a dar sustentação à aprendizagem a partir de avaliação formativa no ensino presencial e no a distância. A utilização adequada de tecnologias de fomento à educação, a interferência pedagógica em avaliação por excelência formativa e processual pode estabelecer resultados de variada ordem como, dentre eles, o favorecimento da aprendizagem em função de melhoria de desempenho escolar, acadêmico e profissional; o incentivo à prática de autoavaliação pelo professor com vistas a perceber o seu nível de qualificação e de experiência para o exercício da docência; e valorização da heteroavaliação pelo professor com vistas a incentivar os alunos à produção de novos e renovados conhecimentos.

PALAVRAS-CHAVE: Avaliação da aprendizagem. Educação presencial. Educação a distância. Tecnologias.

RESUMEN: Este texto tiene por objetivo discutir el papel de la evaluación para el aprendizaje del educando con el uso de las tecnologías, independientemente de la modalidad de enseñanza presencial o a distancia -, y para la variación de instrumentos evaluativos como parte de una planificación que es retroalimentada por las demandas surgidas en el proceso de enseñanza y aprendizaje. El texto se subdivide en dos partes, en que en la primera se enfocan ambientes que necesariamente acuden y ayudan a dar sustentación al aprendizaje a partir de la evaluación formativa en la enseñanza presencial y en la distancia. La utilización adecuada de tecnologías de

\footnotetext{
1 Centro Universitário Internacional (UNINTER), Curitiba - PR. Brasil. Professor titular em cursos de graduação e de pós-graduação presenciais e a distância, pesquisador e escritor; atua no Núcleo de Pesquisa em Educação; é Presidente do Conselho Editorial da Editora Intersaberes (desde 05/2005); é docente no Programa de mestrado em Educação e Novas Tecnologias. E-mail: ivo.b@uninter.com

${ }^{2}$ Universidade Estadual de Ponta Grossa (UEPG), Ponta Grossa - PR - Brasil. Professora do departamento de matemática e estatística. Doutora em Educação. E-mail: marybrandalise@uol.com.br
} 
fomento a la educación, la interferencia pedagógica en evaluación por excelencia formativa y procesal puede establecer resultados de variada orden como, entre ellos el favorecimiento del aprendizaje en función de mejora de desempeño escolar, académico y profesional; el incentivo a la práctica de autoevaluación por el profesor con miras a percibir su nivel de cualificación y de experiencia para el ejercicio de la docencia; y valoración de la heteroavalación por el profesor con miras a incentivar a los alumnos a la producción de nuevos y renovados conocimientos.

PALABRAS CLAVE: Evaluación del aprendizaje. Educación presencial. Educación a distancia. Tecnologías.

ABSTRACT: The objective of this text is to discuss the role of evaluation for the students learning through the use of technologies, regardless of the type of teaching - presential education or distance - and for the variation of evaluation instruments as part of a planning that is fed by the demands that have arisen In the teaching and learning process. The text is subdivided into two parts, in which the first focuses on ambiences that necessarily base and help support learning from formative assessment in face-to-face and distance learning. The adequate use of technologies to promote education, pedagogical interference in evaluation for formative and procedural excellence can establish results of varied order, among them the favoring of learning in function of improvement of academic, academic and professional performance; the incentive to the practice of self-assessment by the teacher in order to perceive their level of qualification and experience for the teaching exercise; and valorization of the heterovaluation by the teacher in order to encourage students to produce new and renewed knowledge.

KEYWORDS: Assessment of learning. Presential education. Distance education. Technologies.

\section{A criação de ambiências para avaliação formativa no ensino presencial e a distância}

Existe uma relação vital entre ensino, avaliação, aprendizagem e as práticas pedagógicas nos ambientes escolares. As salas de aula são espaços e ambientes de aprendizagem por excelência, locais em que as pessoas se reúnem para aprender e ensinar. No entanto, o ato de ensinar é um trabalho que ultrapassa o ambiente físico da sala de aula, e a aprendizagem também é um processo imaterial que ocorre em múltiplos ambientes.

A avaliação, por sua vez, constitui-se em uma investigação crítica de uma determinada situação concebida de forma contextualizada, a fim de desenvolver-se conforme as necessidades da ação pedagógica planejada. Considerar o contexto educacional, nessa perspectiva, vai além do conhecimento da instituição, dos documentos curriculares, mas pressupõe a participação daqueles que fazem parte do processo de ensino-aprendizagem, daqueles que vivenciam e constroem o currículo em ação, ou seja, os professores, os alunos, os gestores. 
Essa ambiência para o desenvolvimento de um processo avaliativo numa perspectiva formativa precisa ser planejada e organizada para o exercício das ações de ensinar e aprender. Concorda-se com Luckesi que:

O ponto de partida para atuar com avaliação é saber o que se quer com a ação pedagógica. A concepção pedagógica guia todas as ações do educador. O ponto de partida é saber onde desejamos chegar em termos da formação do educando. [...] O que é ensinado e aprendido é avaliado, para vir a ser melhor. Para compreender e atuar adequadamente em avaliação da aprendizagem, necessitamos iniciar por esse ponto de partida. (LUCKESI, 2011, p. 27).

A ação pedagógica, tanto na modalidade presencial, semipresencial, como a distância, em termos gerais é constituída de elementos comuns: conteúdos de ensino, objetivos de aprendizagem, critérios de avaliação, instrumentos avaliativos, feedback, resultados. Os objetivos orientam o trabalho docente, por isso é preciso ter clareza das metas estabelecidas no currículo para a formação dos alunos, por que "não é fácil operar na prática de forma coerente com os pressupostos de uma avaliação a serviço da aprendizagem". (CAPPELLETTI, 2007, p. 53).

É certo que avaliação tem um papel muito importante no desenvolvimento da aprendizagem, por isso é essencial adotar uma concepção de avaliação que possa ser desenvolvida de modo a cooperar com a aprendizagem do aluno, levando tanto os educadores quanto os educandos ao aprimoramento das ações propostas e à tomada de decisões educacionais. É importante ressaltar que a

\begin{abstract}
A avaliação (assessment) da aprendizagem, quando bem conduzida e integrada no processo de ensino-aprendizagem, pode contribuir muito para que o estudante aprenda mais e melhor e, além disso, aprenda a pensar, aprenda a aprender, aprenda a ser crítico construtivo e desenvolva a capacidade de controle de sua própria aprendizagem no sentido do seu engrandecimento como ser humano e como cidadão. (VALADARES, 2011, p. 2009).
\end{abstract}

Os conteúdos de ensino (conhecimentos) constituem-se como objeto de ensinoaprendizagem-avaliação. A avaliação efetiva-se ao longo desse processo quando desenvolvida numa perspectiva formativa e tem "a finalidade de fornecer informações que permitam a reorganização do trabalho pedagógico em atendimento às diferenças individuais". (VILLAS BOAS, 2011, p. 17).

A avaliação formativa é um processo planejado em que os profissionais envolvidos, ou seja, os professores, procuram ajustar o trabalho pedagógico conforme as 
evidências coletadas com os alunos. Segundo Villas Boas (2011), essa modalidade de avaliação exige que as ações sejam cuidadosamente organizadas pelo professor com intuito de promover a aprendizagem.

Essa avaliação “engloba as atividades desenvolvidas por professores e/ou seus alunos, as quais fornecem informação a ser utilizada como feedback para modificar as estratégias de ensino e a aprendizagem nas quais eles estão engajados" (BLACK; WILLIAM, 1998, apud VILLAS BOAS, 2011, p. 19), considerando em que ponto da aprendizagem o aluno se encontra. Ou seja, a avaliação é possibilitadora de definição ou redefinição de caminhos diante de ações planejadas e realizadas.

Portanto, a avaliação formativa pressupõe movimento, percurso, passagem, evolução, progressão; pressupõe que os saberes são construídos num processo de negociações e que a tomada de decisões é uma prática constante para ressignificação processual das autorias.

Todo processo avaliativo deve ser necessariamente uma experiência de aprendizagem. Na troca, na interação surgem às semelhanças, as diferenças, as ambiguidades, os conflitos de interesses, enfim, compreender e interpretar os confrontos teóricos/ práticos, as diferentes representações dos envolvidos e suas implicações na reconstrução do objeto em questão são fundamentais na busca da qualidade. (CAPPELLETTI, 2010, p.14).

Embora a avaliação tenha potencial para melhorar a qualidade da aprendizagem de todos os alunos, historicamente, tem atuado mais como uma barreira ao invés de uma oportunidade para os alunos melhorarem a sua aprendizagem. Uma alteração na cultura de avaliação nos ambientes educativos é necessária para promover a avaliação, como parte integrante do processo de ensinoaprendizagem, e estabelecer uma prática de avaliação na sala de aula em função da aprendizagem, ou seja,

A avaliação para a aprendizagem envolve a utilização da avaliação em sala de aula para elevar o rendimento dos alunos, com base na ideia de que estes aprendem mais quando compreendem os objetivos pretendidos para a sua aprendizagem, onde estão em relação a esses objetivos e como podem alcançá-los (preencher as lacunas no seu conhecimento). Ou seja, a avaliação é vista como suporte da aprendizagem e ocorre quando os professores utilizam dados sobre a aprendizagem dos alunos para informar o ensino. (LOPES; SILVA, 2012, p. $3)$. 
Os autores defendem que nessa perspectiva formativa de avaliação a aprendizagem dos alunos é conduzida de forma a levar os alunos a aprender continuadamente e permanecer confiantes de que podem aprender.

A avaliação, nessa perspectiva, enfatiza o papel do aluno no processo educativo, é a avaliação como aprendizagem que acontece quando os alunos refletem sobre como regular os seus avanços para informar os seus futuros objetivos de aprendizagem. Dito de outro modo, enfatiza a responsabilidade dos alunos em relação à aprendizagem e à avaliação, envolvendo-os em processos de auto e heteroavaliação, ou seja, professor e aluno constroem em conjunto a aprendizagem e a avaliação, e (co)constroem formas de acompanhar o progresso da aprendizagem.

Acompanhar e obter informações de qualidade sobre a sua aprendizagem e a dos seus pares e utilizar o feedback que daí resulta para fazer adaptações e ajustes com vista a aumentarem o seu rendimento escolar requer dos estudantes questionamentos reflexivos que possibilitem utilizar o conhecimento pessoal para construir significados e dar sentidos às aprendizagens.

As atividades de avaliação para a aprendizagem e avaliação como aprendizagem têm caráter formativo: a sua finalidade/objetivo é que os alunos melhorem o seu rendimento escolar. Para isso, devem ser partes integrantes do processo de ensino-aprendizagem e fontes de feedback interativo, permitindo aos alunos repensar a sua aprendizagem, ajustá-la e reaprender, (LOPES, SILVA, 2012, p. $5)$.

A avaliação formativa, por um lado, é importante para que os professores conheçam melhor os alunos, façam o planejamento do ensino, ajustando objetivos de aprendizagem às características dos alunos para ajudá-los a desenvolver seu potencial cognitivo. Por outro, é importante para que os alunos compreendam a forma como aprendem e como podem melhorar a própria aprendizagem.

Como afirmam Kenski, Oliveira e Clementino (2006), a avaliação formativa é um processo que acompanha toda trajetória das atividades de ensino, sejam presenciais ou a distância, mediadas pelas mais diferentes tecnologias.

$\mathrm{Na}$ avaliação formativa encontram-se reunidas todas as possibilidades de apoio ao estudante ao longo de sua trajetória, levando em conta seus interesses, aspirações, experiências e reais necessidades. Tal modalidade caracteriza-se pela ocorrência continuada e processual, permeando toda estratégia pedagógica do curso. Ao acompanhar a ação de ensinar e aprender, permite verificar a compatibilidade entre os objetivos direcionadores do processo ensino-aprendizagem e os resultados efetivamente alcançados (KENSKI;OLIVEIRA; CLEMENTINO, 2006, p. 81). 
Enfim, a avaliação formativa é considerada a mais relevante das modalidades avaliativas. Os princípios filosóficos, epistemológicos e metodológicos da avaliação formativa, ou seja, da avaliação para e como a aprendizagem são os mesmos para cursos presenciais e cursos a distância. "A complexidade do ato de avaliar, que aqui não deve ser entendida como o ato de medir ou quantificar o aprendizado, se apresenta nas mesmas proporções tanto na educação a distância como na educação presencial". (PEROSA; SANTOS, 2003, p. 153).

O que muda é a forma de organizá-los e a utilização adequada das tecnologias no processo ensino-avaliação-aprendizagem. A educação escolar precisa se adequar para o uso das tecnologias que lhe são contemporâneas, pois hoje as mudanças políticas, sociais e econômicas provocaram mudanças estruturais nos espaços e tempos de ensinar e aprender.

Nessa direção, Sancho (2010) discute sobre os ambientes virtuais de ensino e aprendizagem e apresenta uma comparação entre o ensino presencial e a distância, nas concepções tradicional e emancipatória ou emergente. A autora explica que na visão tradicional de ensino presencial o ambiente de aprendizagem é a sala de aula, ou seja, é síncrono. Cabe ao professor transmitir a informação, garantindo que o aluno escute, copie e repita de forma adequada nos momentos avaliativos os conhecimentos adquiridos, os quais são realizados na maioria das vezes por meio de provas, testes e exames.

De modo análogo, na visão tradicional de educação a distância o docente ou tutor tem a função de tirar as dúvidas a fim de garantir que os alunos repitam a informação contida nos materiais impressos ou digitais, que lhes é proposto para estudo, e realizem as atividades avaliativas reproduzindo as informações ou conhecimentos aprendidos. $\mathrm{O}$ ambiente de aprendizagem é assíncrono, ou seja, não presencial, com exceção das provas finais que geralmente são presenciais.

Quando apresenta a comparação entre a concepção emergente ou emancipatória de ensino presencial e a distância, Sancho (2010) evidencia que em ambas o papel do professor, e do tutor na $\mathrm{EaD}$, é de facilitador da aprendizagem dos estudantes, orientandoos durante todo o processo de ensino e aprendizagem. Considera que os alunos são responsáveis pelas suas aprendizagens e construtores de conhecimento e de sentidos.

Nessa perspectiva de ensino e aprendizagem a concepção de avaliação é formativa, contínua e processual, com a utilização diversificada de instrumentos, tais como portfólio, ensaios, solução de situações problemas, investigações, entre outros. Caracteriza 
os ambientes de aprendizagens presenciais e virtuais como síncronos e assíncronos, ou seja, nas duas modalidades de ensino as ferramentas tecnológicas virtuais podem ser utilizadas no desenvolvimento curricular. Portanto, em termos gerais, as questões da avaliação da aprendizagem são comuns tanto na educação presencial como na educação a distância.

\begin{abstract}
A problemática da avaliação das aprendizagens é recorrente no contexto educacional e está fortemente associada as concepções de ensino e aprendizagem vigentes em cada momento, as quais se condicionam não só a incidência com que se privilegia uma ou outra função da avaliação função diagnóstica, função formativa ou função sumativa - mas também os instrumentos e as técnicas utilizados com objetivos avaliativos. (GOMES, 2010, p. 313).
\end{abstract}

Há questões particulares e específicas em cada modalidade de ensino, presencial ou a distância, mas sempre será comum num processo avaliativo alguns questionamentos: Quais as finalidades da avaliação? O que será avaliado? Quais são os critérios de avaliação? Qual é o tempo que se dispõe para avaliação? Quais são os instrumentos adequados para a realização da avaliação? Quais aspectos devem ser avaliados? Quem deve avaliar quem? Como os resultados das avaliações serão utilizados?

Criar ambiências (lugares, espaços, tempos) para o desenvolvimento de uma avaliação formativa implica, necessariamente, construir novas formas de avaliar, as quais emergem das percepções de diferentes sujeitos, métodos, instrumentos, inteligibilidades e compreensões, e das suas possibilidades de atuação, criação e intervenção.

As tecnologias de informação e comunicação contemporâneas no currículo podem constituir-se como meios materiais para criação de ambientes de aprendizagem emancipatórios, com uma prática avaliativa formativa. É certo que as TIC podem propiciar benefícios pedagógicos, mas integrá-las às práticas pedagógicas é ainda um grande desafio para as instituições escolares e para os professores.

Como integrar as tecnologias às atividades curriculares a fim de que elas tragam contribuições significativas ao desenvolvimento do processo ensino-aprendizagem? Como as TIC podem ser incorporadas nas práticas pedagógicas não como simples apêndices ou ferramentas tecnológicas, mas como ferramentas cognitivas para que os alunos e educadores "possam manipular e aprender a ler, escrever e comunicar-se usando novas modalidades e meios de expressão e expandir sua capacidade intelectual”? (ALMEIDA; VALENTE, 2011, p. 23). 
Acredita-se que as TIC podem criar novas possibilidades de expressão e comunicação, e também auxiliar na potencialização das práticas pedagógicas para tornar a aprendizagem significativa para os alunos. É necessário, porém, que a aprendizagem seja viabilizada pela tecnologia e não vice-versa. Nessa perspectiva é preciso considerar que

[...] a avaliação da aprendizagem na sala de aula online requer rupturas com o modelo tradicional de avaliação historicamente cristalizado na sala de aula presencial. Se o professor não quiser subutilizar as potencialidades próprias do digital online, ou se não quiser repetir os mesmos equívocos da avaliação tradicional, terá de buscar novas posturas, novas estratégias de engajamento no contexto mesmo da docência e da aprendizagem e aí redimensionar suas práticas de avaliar a aprendizagem a sua própria atuação. (SILVA, 2011, p. 23).

O cuidado com a escolha e a organização de tecnologias específicas para a implementação de cada uma das modalidades de ensino poderá ser fator determinante para a facilitação da aprendizagem. Além do mais, tanto as novas quanto as renovadas tecnologias necessitam ser de domínio público dos professores, dos alunos, bem como dos funcionários técnicos que atuam diretamente nos meios educativos.

Sabe-se que a tecnologia por si só, pouco valor pedagógico consegue agregar aos meios acadêmicos e/ou escolares, no entanto, quando o seu emprego constitui adequação, o desempenho dos alunos poderá ser favorecido.

Cabe aqui reafirmar ainda outro aspecto positivo que vem ocorrendo da parte de professores que atuam no ensino da modalidade a distância: o legado de transferência de tecnologias para a implementação do ensino presencial.

\section{Presencial ou a distância, a boa educação se faz pela avaliação}

Apesar dos lentos avanços que vem sendo conquistados, principalmente nos meios educacionais, com relação a uma avaliação realmente comprometida com a elaboração da aprendizagem, ainda assim tais progressos são muito inconsistentes. Toda a iniciativa avaliativa deve ser concebida e conduzida com a função precípua de facilitar a aprendizagem do estudante.

A partir desse seu posicionamento, pode-se apontar alguns dos benefícios exarados a partir de uma avaliação bem formulada: a) levar o aluno a perceber que a avaliação é oportunidade a mais para a ampliação e o aprofundamento da aprendizagem; b) 
esclarecer que a avaliação estabelece mediação entre o ato da prática docente e o de aprender; c) firmar convicção de que todo o processo avaliativo necessita ser bem preparado, com vistas a envolver todos os principais conteúdos que compreendem um tema.

Entende-se que a avaliação terá garantido maior espaço no objetivo de formulação da aprendizagem, na medida em que o seu conceito for sendo assimilado essencialmente na forma processual. No entanto, tal formulação processual da avaliação não significa abdicar de valores quantitativos, na medida em que esses puderem ser interpretados processualmente para fins de fomento da aprendizagem.

Educação presencial e a distância são duas modalidades educativas que se complementam pedagogicamente nos caminhos da aprendizagem, fazendo-se valer, aos poucos, da avaliação como ponto de partida efetivo de fomento da aprendizagem. Diferenciam-se, sim, em alguns aspectos metodológicos quando da aplicação da avaliação, mas nunca do seu objetivo especial, que é o de favorecer a aprendizagem.

Por isso mesmo, não importa se a implementação da educação ocorre na modalidade presencial ou na a distância, o objetivo a ser cumprido é o mesmo: o de propiciar aprendizagem e desempenho acadêmico de boa qualidade aos alunos.

Em termos de iniciativas de educação a distância-EaD o Brasil ainda se encontra bastante defasado em comparação com vários dos países europeus, além dos Estados Unidos e Canadá, ainda que de alguns anos para cá a EaD venha se consolidando em terras brasileiras. Encontram-se num crescendo as oportunidades de educação a distância por instituições de ensino superior país afora, de modo especial de dependência administrativa privada.

As diferenças maiores existentes entre as duas modalidades de educação residem na aplicação metodológica, na instrumentação tecnológica, no apoio bibliográfico, no sistema de avaliação e na prestação do trabalho de tutoria. No entanto, a qualidade da aprendizagem se equivale quando cada modalidade é bem organizada e implementada no seu respectivo contexto e característica.

Se na educação presencial a relação entre professor e aluno se dá praticamente face a face, mas atingindo um número reduzido de pessoas, na educação a distância essa relação acontece também com razoável empatia, no entanto, com o atingimento de um número infinitamente maior de alunos, simultaneamente, inclusive de comunidades remotas e carentes de recursos educacionais. 
Possivelmente haja interesse em conhecer as diferenças práticas e pedagógicas entre educação presencial e a distância. Tal interesse é louvável, uma vez que ainda existe por um lado certa desconfiança com relação à validade e à qualidade do ensino ofertado na modalidade a distância e, por outro lado, perdura a descrença também referente à qualidade da educação presencial.

\section{Dos instrumentos de avaliação às tecnologias de ontem e de hoje}

Sabe-se não ser absolutamente necessário o uso de instrumentos para proceder à avaliação de desempenho. No entanto, uma vez decidido o seu emprego, que eles sejam variados. De fato, pode-se praticar a avaliação por meio de práticas de observação, de percepção, sem o emprego de instrumentos. No entanto, sabe-se que muitos dos estudantes conseguem demonstrar o seu desempenho de modo especial por meio de instrumentos.

Mesmo assim, não é por meio de qualquer instrumento que certos alunos conseguem demonstrar a sua desenvoltura, mas mediante instrumentos que para eles são especiais. Isto significa que o emprego de instrumentos requer do professor identificar com relação a cada aluno o instrumento com o qual ele consegue demonstrar da melhor maneira os seus conhecimentos; esta realidade demonstra que o professor deve se utilizar de diferentes instrumentos para um mesmo momento de avaliação, seja pela observação, seja por outros meios.

Fica evidente que o emprego de vários instrumentos para uma mesma avaliação exige do professor um trabalho redobrado, mas, se tal fato for para o bem do aluno, que assim seja.

Ainda que a modalidade educativa seja presencial ou a distância, o objetivo avaliativo é comum: identificar a quantas anda o desempenho do aluno. No entanto, cada uma das modalidades educativas demonstra algumas características que as diferenciam em especial em seu formato lógico, a saber:

- educação presencial: a) flexibilidade de emprego de métodos e de metodologias de ensino de acordo com as necessidades escolares do dia-a-dia; b) possibilidade de negociação pontual de interesses acadêmicos com o professor; c) prática de relativa autonomia de estudo; d) capacidade de autodeterminação nem sempre compatível com as necessidades acadêmicas; e) alcance geográfico limitado, o que reduz possibilidades de realização de cursos em nível de graduação e de pós-graduação onde quer que os interesses se manifestem; f) disponibilidade de cursos de formação e 
qualificação em todas as áreas de conhecimento; g) atuação docente por vezes não compatível com algumas exigências acadêmicas, devido à insuficiência de profissionais qualificados para atendimento com igual performance a todas as necessidades educativas.

- educação a distância: a) métodos e metodologias de ensino elaborados especialmente para atenderem a essa modalidade de ensino; b) reduzida possibilidade de negociação entre aluno e professor em aula, o que poderá ser suprido mediante atendimento de tutoria e por mecanismos de comunicação múltipla; c) elevada capacidade de autonomia de estudos pelo aluno; d) elevada capacidade de autodeterminação acadêmica; e) ilimitado alcance geográfico desta modalidade de ensino; f) elevado nível de competência docente; g) diversidade de mecanismos de comunicação com os alunos diminuem sua dependência do professor; h) materiais didáticos elaborados de forma dialógica por especialistas, bem como disponibilidade de tecnologias avançadas que favorecem a aprendizagem; i) fixação dos alunos em seu meio cultural e social, uma vez que a educação a distância encontra-se aí à sua disposição (BOTH, 2012).

Tornou-se usual a expressão "novas" tecnologias, ainda que ela não se sustente de todo, por não representar plena verdade. Isto, porque no rol das "novas" tecnologias encontram-se no mesmo espaço tanto as tecnologias recentes quanto as de existência remota, mas que receberam incremento de atualidade tecnológica. Para fins demonstrativos das ditas novas tecnologias e as tecnologias de performance renovada ou recondicionada, propõe-se os seguintes elencos:

- elenco de algumas das "novas tecnologias": internet e ferramentas da WWW -World Wide Web: rede de alcance mundial; e-book: livro digital; iPad: computador de mão simplificado em comparação ao notebook; iPod: tocador de áudio digital; YouTube: site de carregamento e compartilhamento de vídeos em formato digital; Facebook: website de relacionamento social; e-learning: aprendizagem que ocorre por meios eletrônicos; ambiente virtual de aprendizagem - AVA: ambiente virtual com ferramentas síncronas e assíncronas (ferramentas de comunicação simultânea e não-simultânea), com interface gráfica e acesso via internet;

- elenco de algumas das "renovadas ou acondicionadas tecnologias": o quadro de giz de ontem é o quadro digital de hoje; a transparência de ontem é o slide digital de hoje; o videocassete de ontem é o vídeo digital de hoje; a câmera em VHF/UHF de ontem é a câmera digital de hoje.

Para Kenski (2007, p. 22), as tecnologias não se referem somente a aparelhos e equipamentos. "Na verdade, a expressão 'tecnologia' diz respeito a muitas outras coisas além de máquinas. O conceito de tecnologias engloba a totalidade de coisas que a engenhosidade do cérebro humano conseguiu criar em todas as épocas, suas formas de uso, 
suas aplicações". Para a autora, pouco importa serem novas ou renovadas as tecnologias à disposição da educação, mas, sim, que todas elas de alguma forma favoreçam a aprendizagem e o desempenho. As tecnologias não se bastam a si mesmas, porém, o seu resultado formativo ocorre na sua relação positiva com os conteúdos que dão acabamento ao conhecimento. Já para Behar e outros (2007, p. 3),

[...] evidentemente que não é só devido à introdução das Tecnologias da Informação e Comunicação (TIC) na Educação a Distância (EaD) que está ocorrendo uma crise paradigmática na Educação, mas com ela fica mais evidente e clara a necessidade de realizar mudanças significativas nas práticas educacionais e, consequentemente

Novas, renovadas ou simplesmente antigas, as tecnologias por si só, não patrocinarão melhoria na aprendizagem ou mesmo não haverá interferência pedagógica na avaliação processual sem que a mentalidade de ser professor de boa qualidade se torne uma das máximas educativas.

As tecnologias, seja qual for a sua denominação ou tempo de criação, favorecerão tão melhor a aprendizagem quanto mais adequado for o seu emprego no processo educativo. Iniciativas de avaliação poderão ser consideradas processuais com ou sem o emprego de tecnologias. Assim sendo, não é a presença da tecnologia ou a ausência dela que imprime à avaliação maior ou menor status de processualidade.

Processo representa ação de continuidade sem interrupção, nem percalços. Processo pode ser simbolicamente comparado a uma tira elástica que, mesmo que paulatinamente esticada, não apresenta interrupção de percurso. As tecnologias servem de apoio à consecução de processo avaliativo melhorado. Dessa forma, pode-se antever que a interferência pedagógica na avaliação processual com o uso de tecnologia é deveras positiva.

Se porventura algum deslize pedagógico ocorrer nesse processo, tal deve-se possivelmente à incorreção do uso da tecnologia. Em face dessa possibilidade pode-se apontar algumas razões que aí podem resultar, como: a) escolha errônea da tecnologia empregada; b) uso inconveniente da tecnologia eleita; c) insuficiente aproveitamento das potencialidades da tecnologia utilizada.

Por outro lado, a interferência pedagógica na avaliação processual com o uso adequado de tecnologias pode conduzir a resultados educativos nomeadamente positivos, como: a) percepção e emprego da avaliação como processo de apoio e de favorecimento da 
aprendizagem, em especial; b) inversão gradual da mentalidade estudantil a respeito do principal objetivo da avaliação, que é o da valorização do desempenho escolar e acadêmico em detrimento da supervalorização do conceito e da nota.

$\mathrm{O}$ fator tecnologia faz diferença maior em ambientes de aprendizagem, de modo especial em ambientes de educação a distância. No entanto, para o bem da educação na modalidade presencial, a transferência de tecnologia também está se tornando realidade sempre mais promissora. Os professores que atuam em educação na modalidade a distância estão se tornando os maiores e melhores porta-vozes da transferência e aplicação de tecnologias no desenvolvimento da educação na modalidade presencial.

Nem sempre os ambientes escolares de educação presencial estão equipados com tecnologias avançadas como os da educação a distância, mesmo assim boa parte dos professores que as dominam consegue se valer das mesmas de maneira bastante qualificada, por conta de experiências adquiridas na $\mathrm{EaD}$.

Tal fato sugere um ganho de boa qualidade para a educação presencial. Além do mais, pela socialização e a consequente familiarização das diferentes tecnologias ao alcance de um sempre maior contingente populacional, os alunos que adentram os ambientes educativos dos diferentes níveis escolares também estão em condições de contribuir com o domínio das principais ferramentas tecnológicas.

Assim sendo, na medida em que professores e alunos demonstrem sempre maior domínio das principais ferramentas tecnológicas a serviço da educação, o título deste texto "Interferência pedagógica na avaliação da aprendizagem no ensino presencial e a distância com o uso de tecnologias" se verá progressivamente justificado e até fortalecido como indicador de boa qualidade educativa.

Com o uso exemplar de tecnologias de fomento à educação, a interferência pedagógica em avaliação por excelência processual pode estabelecer resultados de variada ordem como, entre outros: a) favorecimento da aprendizagem em função de melhoria de desempenho escolar, acadêmico e profissional; b) incentivo à prática de autoavaliação pelo professor com vistas a perceber o seu nível de qualificação e de experiência para o exercício da docência; c) valorização da heteroavaliação pelo professor com vistas a incentivar os alunos à produção de novos e renovados conhecimentos.

A preocupação com as possibilidades de interferência pedagógica na avaliação processual com o uso de tecnologias é feito acadêmico positivamente plausível e recomendável. E sabe-se que a referida interferência pedagógica age com tanta maior 
propriedade na avaliação de caracterização processual, quanto melhor forem trabalhadas as tecnologias no processo de aprendizagem.

\section{REFERÊNCIAS}

ALMEIDA, Maria Elizabeth Bianconcini de.; VALENTE, José Armando. Tecnologias e currículo: trajetórias convergentes ou divergentes? São Paulo: Paulus, 2011.

BEHAR, P. A.; PASSERINO, L.; BERNARDI, M. Modelos pedagógicos em educação a distância. RENOTE: Revista Novas Tecnologias na Educação, Porto Alegre, v. 5, p. 3. 2007.

BOTH, Ivo José. Avaliação: voz da consciência da aprendizagem. Curitiba, PR: IBPEX, 2. Ed., série 2. 2012, 246p.

CAPPELLETTI, Isabel Franchi. Avaliação a serviço da aprendizagem: um inédito viável. In: Avaliação da aprendizagem: discussão de caminhos. São Paulo: Editora Articulação Universidade/Escola, 2007, p. 41-56.

CAPPELLETTI, Isabel Franchi. Avaliação e Currículo: políticas e projetos. São Paulo: Editora Articulação Universidade/Escola, 2010, p. 41-56.

GOMES, Maria João. Problemáticas da avaliação em educação online. In: SILVA, Marco.; PESCE, Lucila, ZUIN, Antonio (Orgs.). Educação Online: cenário, formação e questões didático-pedagógicas. Rio de Janeiro: Wak Ed., 2010, p. 309-336.

HADJI, Charles. A avaliação, regras do jogo: das intenções aos instrumentos. Porto: Porto Editora, 1994.

KENSKI, Vani Moreira.; OLIVEIRA, Gerson Pastre.; CLEMENTINO, Adriana. Avaliação em movimento: estratégias formativas em cursos online. In: Avaliação da aprendizagem em curso online. São Paulo: Edições Loyola, 2006, p.79-89.

KENSKI, Vani Moreira. Educação e tecnologias: o novo ritmo da informação. Campinas, SP: Papirus. 2007.

LOPES, José.; SILVA, Helena Santos. 50 Técnicas de avaliação formativa. Edições Lidel: Porto, 2012.

LUCKESI, Cipriano Carlos. Avaliação da aprendizagem: componente do ato pedagógico. São Paulo: Cortez, 2011.

PEROSA, Gilse T. Lazzari.; SANTOS, Marcelo dos. Interatividade e aprendizagem colaborativa em um grupo de estudo online. In: SILVA, Marco (Org.). Educação Online. São Paulo: Edições Loyola Jesuítas. 2. ed., 2011, p. 149-156. 
SANCHO, Juana M. Para promover o debate sobre ambientes virtuais de ensino e aprendizagem. In: SILVA, M.; PESCE, L.; ZUIN, A. (orgs.). Educação online: cenário, formação e questões didático-metodológicas. Rio de Janeiro: Edições Loyola, 2010

VALADARES, Jorge. Teoria e prática de educação a distância. Lisboa: Aberta, 2011.

VILLAS BOAS, Benigna Maria de Freitas. Práticas inovadoras. Campinas: Papirus, 2011.

\section{Como citar este artigo:}

BOTH, Ivo José.; BRANDALISE, Mary Ângela Teixeira. Interferência pedagógica na avaliação da aprendizagem no ensino presencial e a distância com o uso de tecnologias. Revista Ibero-Americana de Estudos em Educação, Araraquara, v. 13, n. 2, p. 807-821, abr./jun., 2018. E-ISSN: 1982-5587. DOI: 10.21723/riaee.v13.n2.2018.9924

Submissão em: 29/05/2017

Aprovação final em: 02/07/2017 